Check for updates

Cite this: RSC Adv., 2018, 8, 20095

\title{
Opal promotes hydrothermal carbonization of hydroxypropyl methyl cellulose and formation of carbon nanospheres
}

\begin{abstract}
Yuanjun Xu, Maosheng Xia, Yinshan Jiang, Fangfei Li and Bing Xue (DD *
Hydrothermal carbon nanospheres were prepared by introducing opal into the hydrothermal carbonization system of hydroxypropyl methyl cellulose (HPMC). Then the effects of opal on hydrothermal carbonization of HPMC were investigated after different reaction durations (105-240 $\mathrm{min}$ ). The reaction products were characterized by elemental analysis, gas chromatography-mass spectrometry (GC-MS), scanning electron microscopy (SEM), energy dispersive X-ray spectroscopy (EDS), Fourier transform infrared spectroscopy (FT-IR) and $\mathrm{N}_{2}$ adsorption-desorption. Results of elemental analysis indicated that the $\mathrm{H}$ (hydrogen) and $\mathrm{O}$ (oxygen) content of HPMC decreased through dehydration, demethylation, decarbonylation and hydrolysis reactions, forming hydrochar with higher carbon content. The addition of opal was confirmed to accelerate the hydrolysis of HPMC. $\mathrm{N}_{2}$ adsorption-desorption tests and SEM analysis showed that opal with a large specific surface area adsorbed HPMC hydrolysis products, such as furans, and facilitated furan cyclodehydration on its surfaces to form cross-linked carbons, which contributed to the quick formation of hydrochar. Moreover, the adsorption by opal also inhibited hydrochar aggregation, so the final hydrothermal carbon spheres had sizes of 20-100 nm.
\end{abstract}

Received 6th February 2018
Accepted 19th May 2018

DOI: $10.1039 / c 8 r a 01138 a$

rsc.li/rsc-advances and cleavage of lignocellulose. ${ }^{\mathbf{1 8 , 1 9}}$ Addition of inorganic salts (e.g. $\mathrm{CaCl}_{2}, \mathrm{LiCl}, \mathrm{MgCl}_{2}$ ) into lignocellulose could reduce hydrothermal vapor, catalyze biomass degradation, and increase the higher heat value (HHV) and energy density of products. ${ }^{18,20,21}$ Furthermore, researchers paid more attention to how types of minerals would affect the HTC of biomass. In recent years, more and more attentions have been paid to hightemperature pyrolysis improved by addition of minerals into biomass (cellulose) systems. As reported, the presence of minerals promotes biomass (cellulose) degradation, accelerates primary and secondary cellulose decompositions, and promotes the formation of numerous small-molecule substances. ${ }^{21,22}$ Meanwhile, the minerals contained in biomass components also lower the decomposition temperature of biomass (lignin, nutshell), increase gas production rates and decrease char production. $^{21,22}$ There are many examples in nature that minerals affect biomass conversion. Through HTC experiments, $\mathrm{Wu}$ et al. confirmed the montmorillonite in biomass could catalyze the cellulose conversion into oil-prone kerogen products. ${ }^{23}$ Regarding geological effects, this is an important reaction for fossil fuel formation and accumulation. However, the mechanisms how newly-added minerals affect biomass and yield rate of solid product with HTC time have not been profoundly studied. Thus, relevant research is needed to further understand the special roles of minerals in HTC and optimize synthesis parameters of the formation of biomass carbon. Such researches provided references for the wide application of biomass carbon.
Key Laboratory of Automobile Materials, Ministry of Education, Department of Materials Science and Engineering, Jilin University, No. 5988 People's Avenue, Changchun 130025, People's Republic of China. E-mail: xuebing2011@jlu.edu.cn; Fax: +86-0431-85094856; Tel: +86-0431-85094856 
In this work, volcanic opal shale was selected as the amorphous $\mathrm{SiO}_{2}$ additive. Then the effects of minerals on biomass along with the HTC of hydroxypropyl methyl cellulose (HPMC) were investigated. The HTC system was studied through element analysis, GC-MS, SEM, EDS, FT-IR and $\mathrm{N}_{2}$ adsorptiondesorption tests. The specific research contents were listed as follows (1) production yields of hydrochar and element distributions of residual solid products; (2) effects of opal on morphology and structures of products; (3) effects of opal on composition of filtrates; (4) mechanism of residual solid product formation.

\section{Experimental}

\section{Materials}

HPMC (analytical reagent) was purchased from Yanxing Industrial Co., Ltd. Opal came from Nenjiang watershed, north of Inner Mongolia, China, and it was composed of $90.24 \% \mathrm{SiO}_{2}$, 3.66\% $\mathrm{Al}_{2} \mathrm{O}_{3}, 0.33 \% \mathrm{MgO}, 0.83 \% \mathrm{TFe}_{2} \mathrm{O}_{3}, 0.56 \% \mathrm{~K}_{2} \mathrm{O}, 0.30 \%$ $\mathrm{CaO}, 0.10 \% \mathrm{TiO}_{2}, 0.30 \% \mathrm{P}_{2} \mathrm{O}_{5}$ and $0.21 \% \mathrm{Na}_{2} \mathrm{O}$. Opal was dried and passed through a 100-mesh square-hole sieve before the HTC experiment.

\section{HTC}

HTC experiments were carried out in $100 \mathrm{~mL}$ static stainless steel Teflon-lined autoclave reactor. In mineral-free experiments (HPMC system), each reactor was added with $3 \mathrm{~g}$ of HPMC and $30 \mathrm{~mL}$ of deionized water under stirring, and then heated in a DGG-9070B electric constant temperature drying oven (Shanghai Sende Laboratory Instrument Co., Ltd.) at $230{ }^{\circ} \mathrm{C}$. The reactors were taken out one-by-one at certain interval, cooled to room temperature, and vacuum-filtrated. The residual solid products were dried at $80{ }^{\circ} \mathrm{C}$ for $24 \mathrm{~h}$ until reaching constant weight and the filtrate was reserved for analysis. In the mineral-added experiments (HPMC/opal system), the procedures were the same except for the addition of $0.9 \mathrm{~g}$ of opal in the reactor. The sampling time was 105, 120, 150,180 and $240 \mathrm{~min}$, respectively. The residual solid products of HPMC systems were named as $\mathrm{H}-X$, where $X$ represented the sampling time. The residual solid products of HPMC/opal systems were named as HMC- $X$. For instance, HMC-150 represented the product from the HPMC/opal system after 150 min of reaction.

\section{Demineralization}

The presence of opal in HMC- $X$ would affect the analytical accuracy of HTC products (hydrochar), so the opal in HMC- $X$ should be removed before analysis. Hence, the $\mathrm{HCl} / \mathrm{HF}$ mixed acid dissolution method was used, which contained a $3 \mathrm{~mol} \mathrm{~L}^{-1}$ $\mathrm{HCl}$ solution and a $4.45 \mathrm{~mol} \mathrm{~L}{ }^{-1} \mathrm{HF}(10 \mathrm{wt} \%)$ solution mixed at the volumetric ratio of $1: 2$. Each time $0.3 \mathrm{~g}$ of HMC- $X$ was added into $30 \mathrm{~mL}$ of the mixed acid solution under magnetic stirring for $8 \mathrm{~h}$, followed by centrifugation. The centrifugal products were washed with deionized water several times until reaching $\mathrm{pH}=7$, and then dried at $80{ }^{\circ} \mathrm{C}$ until reaching constant weight. At this moment, the demineralized product was named $\mathrm{D}-X . \mathrm{H}-X$ was also conducted by the same demineralization treatment, in order to analyze the influence of strong acid on $\mathrm{H}-X$. The demineralized product of $\mathrm{H}-X$ was named as A$X$.

\section{Characterization}

FT-IR spectra were performed on a Nexus 670 spectroscope (USA) at $400-4000 \mathrm{~cm}^{-1}$ and with $\mathrm{KBr}$. To compare the functional group strengths, $0.5 \mathrm{mg}$ of solid product and $200 \mathrm{mg}$ of KBr were used for quantitative analysis. The surface morphologies of raw materials and residual solid products (sampled at $105,150,240 \mathrm{~min}$ ) were characterized on an XL-30 environmental SEM instrument (FEI company, USA). Energy dispersive X-ray spectrometer (EDS) detector (X-MAX, OXFORD instruments, England) combined with XL-30 environmental SEM was used to analyze HMC-240. Specific surface areas were measured by the multipoint Brunauer-Emmett-Teller (BET) method. The volumes/diameters of micropores and mesopores were detected by the Barrett-Joyner-Halenda (BJH) method. The specific surface area and pore size instrument was bought from Beijing JWGB SCI \& Tech Co. Ltd. (JW-BK222). Hydrothermal liquids were detected by a QP2010SE GC-MS meter (Shimadzu, Japan). Elements of raw materials and solid residues were analyzed on a CHN element analyzer (Vario EL cube, CHN, Germany). Mainly D- $X$ and $\mathrm{H}-X$ were tested.

\section{Results and discussion}

\section{Hydrochar production yields}

The hydrochar production yields of $\mathrm{H}-X$ and $\mathrm{D}-X$ were calculated as follows:

$$
\text { Hydrochar yield }(\%)=\frac{W_{1}(\mathrm{~g})}{W_{\mathrm{HPMC}}(\mathrm{g})} \times 100 \%
$$

Hydrochar-mineral complexes without opal yield $(\%)=$

$$
\frac{W_{2}(\mathrm{~g})-W_{\text {opal }}(\mathrm{g})}{W_{\text {HPMC }}(\mathrm{g})} \times 100 \%
$$

where $W_{1}$ is the weight of $\mathrm{H}-X ; W_{2}$ represents the weight of HMC- $X ; W_{\text {opal }}$ is the weight of opal added into HPMC; $W_{\text {HPMC }}$ stands for the weight of initial feedstock HPMC.

Fig. 1 displays the hydrochar production yields of $\mathrm{H}-X$ or D- $X$ after different reaction durations (defined no hydrochar production formed at $0 \mathrm{~min}$ ). Clearly, the production yields from $\mathrm{H}-X$ first decrease and then increase with time, while the production rates of $\mathrm{D}-X$ increase all the time. The HTC of HPMC mainly consists of two stages. The first procedure includes organic matter dehydration, dehydroxylation, the hydrolysis of HPMC into small molecules and HPMC solubilization; ${ }^{\mathbf{8}, 12}$ the weight of the resulting residual solid products gradually decreases. The second procedure is the repolymerization of small molecules in solution into hydrochar. ${ }^{24}$ For $\mathrm{H}-X$, the first procedure does not end after $105 \mathrm{~min}$, so the weight of resulting residual solid products gradually decreases with the prolonging of time. The increase in the weight of residual solid products after $120 \mathrm{~min}$ indicates the second procedure already has 


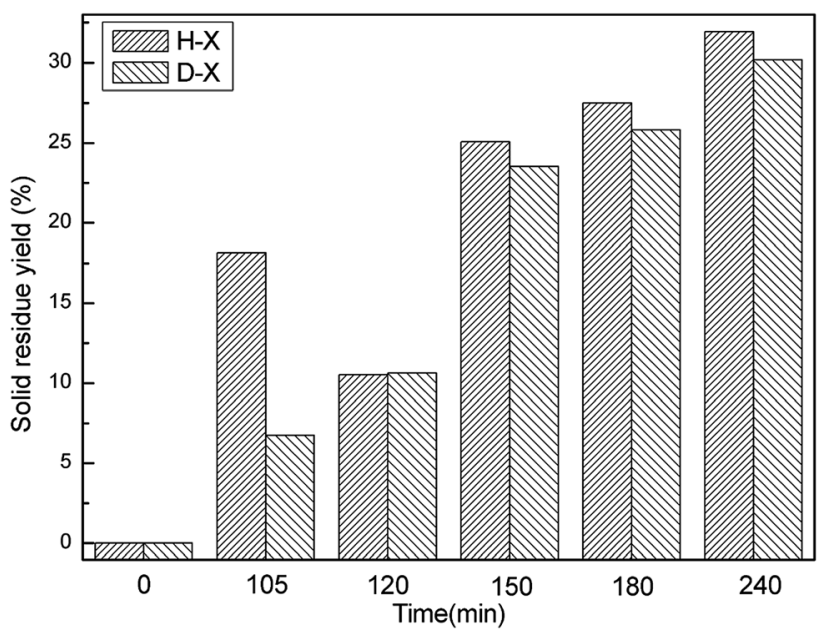

Fig. 1 Calculated yields of $H-X$ and $D-X$.

started, so the weight of resulting hydrochar increases with time. For D- $X$, the weight of solid products always rises from 105 to $240 \mathrm{~min}$; analysis of D-105 suggests the first procedure may be almost finished and the second one has gradually started after $105 \mathrm{~min}$. It is also indicated the presence of opal could accelerate the first procedure and facilitate the dissolution of HPMC in water. Meanwhile, the H-120 and D-120 both transform into hydrochar at $120 \mathrm{~min}$.

\section{Element analysis of hydrochar}

Table 1 shows the element composition $(\mathrm{C}, \mathrm{H}, \mathrm{N}, \mathrm{O})$ and atomic ratios $(\mathrm{H} / \mathrm{C}, \mathrm{O} / \mathrm{C})$ of HPMC, $\mathrm{D}-X$ and $\mathrm{H}-X$. The carbon contents increase from $46.05 \%$ in $\mathrm{HPMC}$ to $70.77 \%$ in $\mathrm{H}-\mathrm{X}(\mathrm{H}-240)$ and to $69.91 \%$ in D- $X$ (D-240). Meanwhile, the $\mathrm{O}$ and $\mathrm{H}$ contents in the residual solid products are both significantly smaller. The atomic $\mathrm{H} / \mathrm{C}$ and $\mathrm{O} / \mathrm{C}$ ratios, which are 1.83 and 0.76 in HPMC respectively, decrease to 0.76 and 0.26 in $\mathrm{H}-X$, respectively. And the $\mathrm{H} / \mathrm{C}$ and $\mathrm{O} / \mathrm{C}$ atomic ratios of $\mathrm{D}-X$ decrease from 1.83 to 0.76 and 0.74 to 0.28 respectively (Table 1 ). Above results indicate these changes are similar between $\mathrm{H}-X$ and $\mathrm{D}-X$ at last. These results suggest that the polycondensation of hydrochar and the carbonization are both gradually intensified with time.

Table 1 Elemental composition of HPMC, $\mathrm{H}-\mathrm{X}$ and $\mathrm{D}-\mathrm{X}$ under different hydrothermal carbonization time

\begin{tabular}{lllllll}
\hline Samples & $\mathrm{C}(\mathrm{wt} \%)$ & $\mathrm{H}(\mathrm{wt} \%)$ & $\mathrm{N}(\mathrm{wt} \%)$ & $\mathrm{O}(\mathrm{wt} \%)$ & $\mathrm{H} / \mathrm{C}$ & $\mathrm{O} / \mathrm{C}$ \\
\hline HPMC & 46.05 & 7.04 & 0.00 & 46.91 & 1.83 & 0.76 \\
H-105 min & 50.64 & 7.62 & 0.00 & 41.74 & 1.80 & 0.62 \\
D-105 min & 58.85 & 6.23 & 0.00 & 34.92 & 1.27 & 0.45 \\
H-120 min & 66.53 & 5.07 & 0.00 & 28.40 & 0.91 & 0.32 \\
D-120 min & 65.28 & 4.83 & 0.00 & 29.89 & 0.89 & 0.34 \\
H-150 min & 69.92 & 4.65 & 0.00 & 25.43 & 0.80 & 0.27 \\
D-150 min & 68.52 & 4.58 & 0.00 & 26.90 & 0.80 & 0.29 \\
H-180 min & 71.15 & 4.58 & 0.00 & 24.27 & 0.77 & 0.26 \\
D-180 min & 68.52 & 4.58 & 0.00 & 26.90 & 0.80 & 0.29 \\
H-240 min & 70.77 & 4.50 & 0.00 & 24.73 & 0.76 & 0.26 \\
D-240 min & 69.91 & 4.30 & 0.00 & 25.79 & 0.74 & 0.28
\end{tabular}

However, the element composition and atomic ratios $(\mathrm{H} / \mathrm{C}, \mathrm{O} / \mathrm{C})$ of D-105 is different from $\mathrm{H}-105$, indicating the formation of hydrochar is accelerated under the effect of opal.

The evolutions of $\mathrm{H} / \mathrm{C}$ and $\mathrm{O} / \mathrm{C}$ atomic ratios can be illustrated by the representative reaction pathways in the Van Krevelen diagram (Fig. 2). Samples correspond to different state points on the figure based on the atomic $\mathrm{H} / \mathrm{C}$ and $\mathrm{O} / \mathrm{C}$ ratios, so when the positions of state points are changed due to the alteration of preparation conditions, the migration of arrowhead at a specific direction indicates the occurrence of corresponding reaction of dehydration, demethylation or decarbonylation. ${ }^{\mathbf{1 2 , 2 5}}$ With the reaction time from 105 to $120 \mathrm{~min}$, the $\mathrm{H} / \mathrm{C}$ and $\mathrm{O} / \mathrm{C}$ ratios of $\mathrm{H}-X$ rapidly decrease (Fig. 2). The state point of $\mathrm{H}-105$ migrates largely along the dehydration line to the state point of $\mathrm{H}-120$, but almost do not change at the demethylation or decarbonylation line, indicating HPMC is fast dehydrated during this period and demethylation or decarbonylation nearly do not occur. The changes of D- $X$ and $\mathrm{H}-X$ are almost the same, as they are all fast dehydrated. ${ }^{12}$ With the prolonging of time, the $\mathrm{H} / \mathrm{C}$ and $\mathrm{O} / \mathrm{C}$ ratios decrease slowly until reaching a balance for both $\mathrm{H}-X$ and $\mathrm{D}-X$, and the migrating distances of the corresponding state points are gradually shortened, indicating demethylation and decarbonylation reactions are ignorable at this moment. However, the dehydration rate of D-105 is faster than H-105. In predecessors' research, methylisobutylketone (MIBK) was used to extract hydroxymethyl furfural (HMF) immediately, thus promoting the dehydration reaction by shifting the equilibrium towards the formation of $\mathrm{HMF} .{ }^{26}$ Because of the better absorption ability of opal, opal can also be introduced to adsorb the soluble production, therefore accelerating the dehydration reaction by shifting the equilibrium to the dehydrated production.

In this paper, it has been found that the reaction pathways are occurred at the earlier period of HTC process. The research of Xiaowei Lu et al. ${ }^{8}$ demonstrates that reaction temperature is the major parameter to influence the transformation of cellulose, while the long duration time only has delicate impact on reaction pathways of hydrothermal carbonization of cellulose such as dehydration and decarbonylation. The phenomenon has also been found by the study of Chao He et al. ${ }^{\mathbf{1}}$ These results

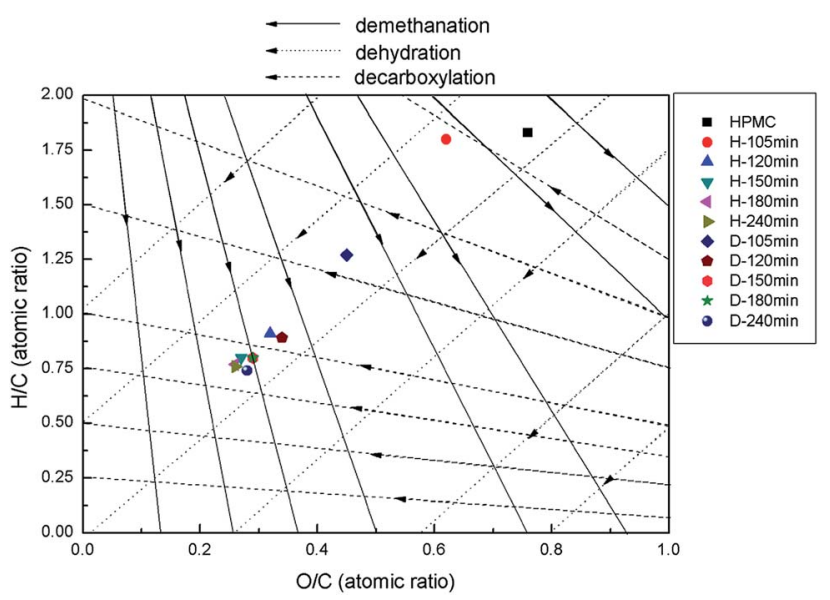

Fig. $2(\mathrm{H} / \mathrm{C})-(\mathrm{O} / \mathrm{C})$ of HPMC, $\mathrm{H}-\mathrm{X}$ and $\mathrm{D}-\mathrm{X}$ in Van Krevelen diagram. 
indicate that the reaction pathways of biomass mainly happen in the early stage of HTC process.

\section{FT-IR analysis of hydrothermal carbonized products}

Fig. 3 displays the FT-IR spectra of hydrochar. The FT-IR spectra of HPMC show peaks at $3427,2922,2850 \mathrm{~cm}^{-1}$ (stretching vibrations of $-\mathrm{OH},-\mathrm{CH}_{2},-\mathrm{CH}_{3}$, respectively); $1638 \mathrm{~cm}^{-1}$ (adsorbed water from environment); $1480 \mathrm{~cm}^{-1}$ (stretching vibration of $\mathrm{C}=\mathrm{O}$ stands for carbonyl groups in HPMC); 1385, $940 \mathrm{~cm}^{-1}$ (characteristic of $-\mathrm{CH}$ ). ${ }^{\mathbf{1 , 3 , 2 7 , 2 8}}$ With the proceeding of reaction, the FT-IR spectra of $\mathrm{H}-X$ are gradually changed in Fig. 3a. The FT-IR spectral lines of H-105 has a little different with HPMC such as the increasement of peak intensity at $1060 \mathrm{~cm}^{-1}$ (C-O stretching vibration) and the shift of $-\mathrm{CH}$ from $1385 \mathrm{~cm}^{-1}$ (HPMC) to $1400 \mathrm{~cm}^{-1}$ (H-105), indicating the structure of HPMC has started to transform, the HPMC has been converted into hydrochar after $105 \mathrm{~min}$ of reaction. The FT-IR spectra of $\mathrm{H}-120$ show new peaks at $1700 \mathrm{~cm}^{-1}$ (stretching vibration of $\mathrm{C}=\mathrm{O}$ ); $1620,1513 \mathrm{~cm}^{-1}$ (stretching vibration of $\mathrm{C}=$ C); $797 \mathrm{~cm}^{-1}$ (C-H out-of-plane bending vibrations in aromatic chemicals). ${ }^{12,25,28}$ Along with the prolonging of time, the three vibration peaks become increasingly more evident in $\mathrm{H}-150, \mathrm{H}$ 180 and $\mathrm{H}-240$. These results suggest dehydration of HPMC has occurred to form carbonyl and carboxyl groups after 120 min of reaction, which confirms the generation of hydrochar. Fig. $3 \mathrm{~b}$ shows the FT-IR spectra of A-H. There is no difference between the FT-IR spectra of A-H with $\mathrm{H}-X$, indicating slight influence on the $\mathrm{H}-X$ by demineralization treatment. The FT-IR spectra in Fig. $3 \mathrm{c}$ are not largely different between $\mathrm{D}-X$ and $\mathrm{H}-X$, but the vibration peaks characteristic of hydrochar at 1700, 1513 and $797 \mathrm{~cm}^{-1}$ already appear after $105 \mathrm{~min}$ in $\mathrm{D}-X$. This result indicates the formation of hydrochar is earlier than that in the opal-free systems, indicating the presence of opal could accelerate the dehydration of HPMC and thereby promote the formation of hydrochar. Fig. 3d shows the peaks of opal shale at $3440,1630 \mathrm{~cm}^{-1}$ (stretching vibration and bending vibration of $-\mathrm{OH}$, respectively), $1100 \mathrm{~cm}^{-1}$ (asymmetric stretching vibration of $\mathrm{Si}-\mathrm{O}-\mathrm{Si}$ ), $793 \mathrm{~cm}^{-1}$ (stretching vibration of $\mathrm{Si}-\mathrm{OH}$ ) and $475 \mathrm{~cm}^{-1}$ (bending vibration of $\mathrm{Si}-\mathrm{O}-\mathrm{Si}$ ). ${ }^{27,29-32}$ Peaks at $1700 \mathrm{~cm}^{-1}$ (stretching vibration of $\mathrm{C}=\mathrm{O}$ ) and $1513 \mathrm{~cm}^{-1}$ (stretching vibration of $\mathrm{C}=\mathrm{C}$ ) also present in Fig. 3d. These phenomena suggest that hydrochar and opal may couple with each other. ${ }^{31-34}$

\section{Morphology and EDS analysis of HTC products}

Fig. 4 shows the morphology of solid products at different time points. SEM shows that opal exists as a villous cluster shape (Fig. 4a), which can be magnified to be a structure consisting of numerous irregular layers. This unique structure endows opal with very low density and large specific surface area. In
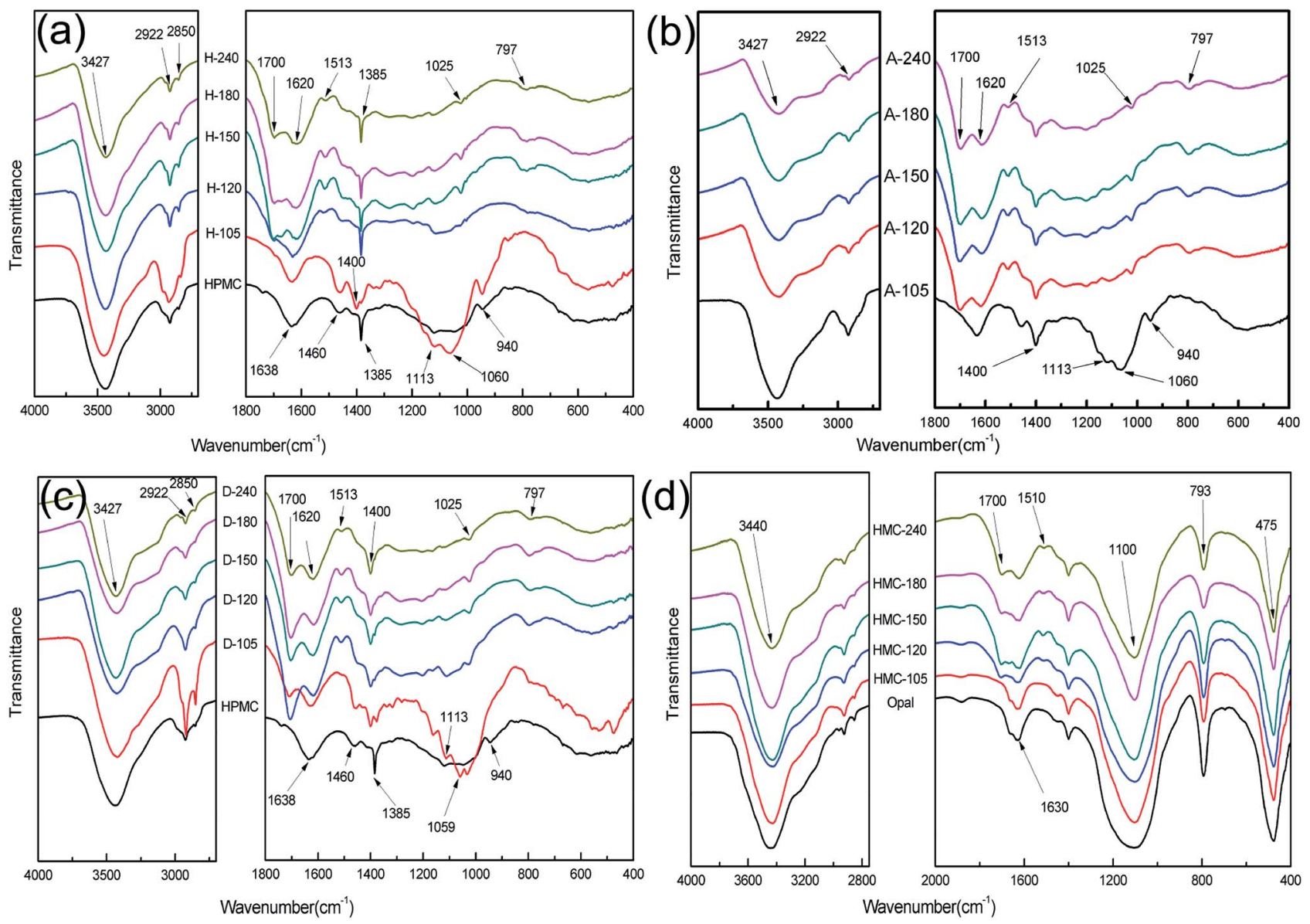

Fig. 3 FT-IR spectra of (a) H-X; (b) A-X; (c) D-X and (d) HMC-X after different reaction durations. 
comparison, HPMC exists as a porous micellar structure composed of fiber-like substances (Fig. 4b)., ${ }^{3,25}$ The morphology of HPMC after HTC has considerably changed. After treatment at $230{ }^{\circ} \mathrm{C}$ for $105 \mathrm{~min}$, the "porous micelles" has already merged together (Fig. 4c), which reduces the porosity of HPMC. Under same conditions, the addition of opal leads to the complete disappearance of porous micelles from HPMC, and instead fine particles have been formed on surfaces of opal (Fig. 4d). ${ }^{35}$ At $150 \mathrm{~min}$, numerous spherical substances (which have also been identified as hydrochar by element analysis and FT-IR) become more evident in the HPMC systems (Fig. 4e and 5a). These hydrothermal carbon spheres are non-uniform in sizes, as the large spheres are $5-10 \mu \mathrm{m}$ with smooth surfaces; while the small spheres are $0.4-0.7 \mu \mathrm{m}$ with irregular appearance and have adhered at edges. ${ }^{36}$ At $240 \mathrm{~min}$, the large spheres become slightly larger in sizes and smoother on surfaces, and tend to be homogeneous (Fig. $4 \mathrm{~g}$ and $5 \mathrm{c}$ ). These changes are similar to the hydrochar converted from glucose, fructose or sucrose. ${ }^{11,37,38}$ In the HPMC/opal systems, the morphology of products has changed significantly. At $150 \mathrm{~min}$, spherical hydrochar, but very little and small $(<1 \mu \mathrm{m})$, is also found in the products, but more particles $(20-100 \mathrm{~nm})$ are adsorbed onto opal surfaces (Fig. 4f and $5 \mathrm{~b}$ ), which are largely different from the HPMC systems. At $240 \mathrm{~min}$, in addition to the small spheres $(<1 \mu \mathrm{m})$, large spheres $(5-10 \mu \mathrm{m})$ also appear, while the bulk density of particles on opal surfaces increases, but with smaller particle size (Fig. $4 \mathrm{~h}$ and $5 \mathrm{~d}$ ). These results indicate the presence of opal significantly inhibits the growth of hydrothermal carbon spheres and restricts the ball sizes at the nanoscale. The formation of hydrochar involves the hydrolysis of HPMC and the repolymerization of hydrolysates. As for hydrochar production rates, the presence of opal considerably facilitates the hydrolysis of HPMC, and the larger specific surface area contributes to the adsorption of hydrolysis products from the liquid phase and accelerates the sedimentation of polymer products., ${ }^{4,23}$ Moreover, the interaction between surface silicon hydroxyl and
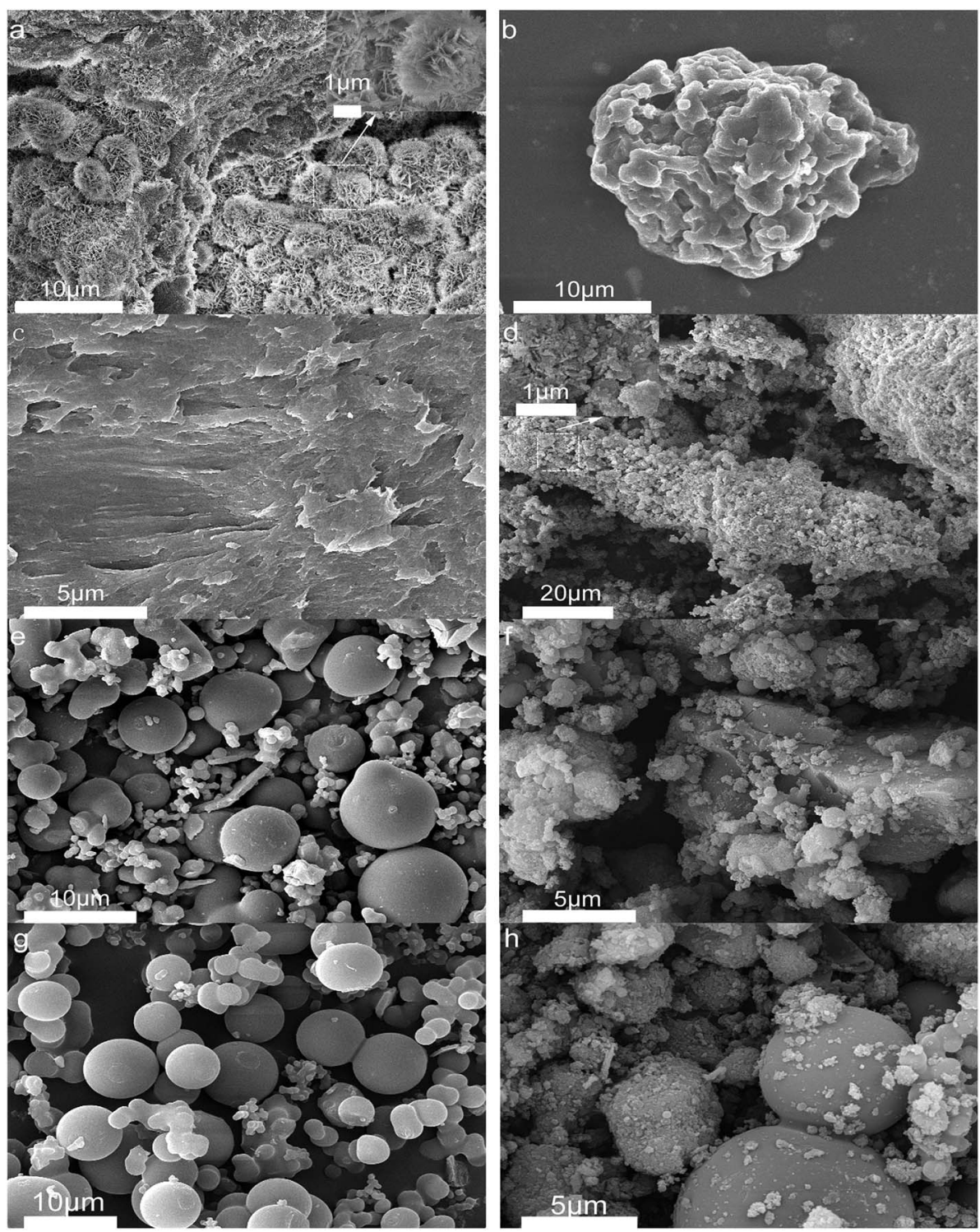

Fig. 4 SEM images (a) raw opal; (b) HPMC; (c) H-105; (d) HMC-105; (e) H-150; (f) HMC-150; (g) H-240 and (h) HMC-240. 

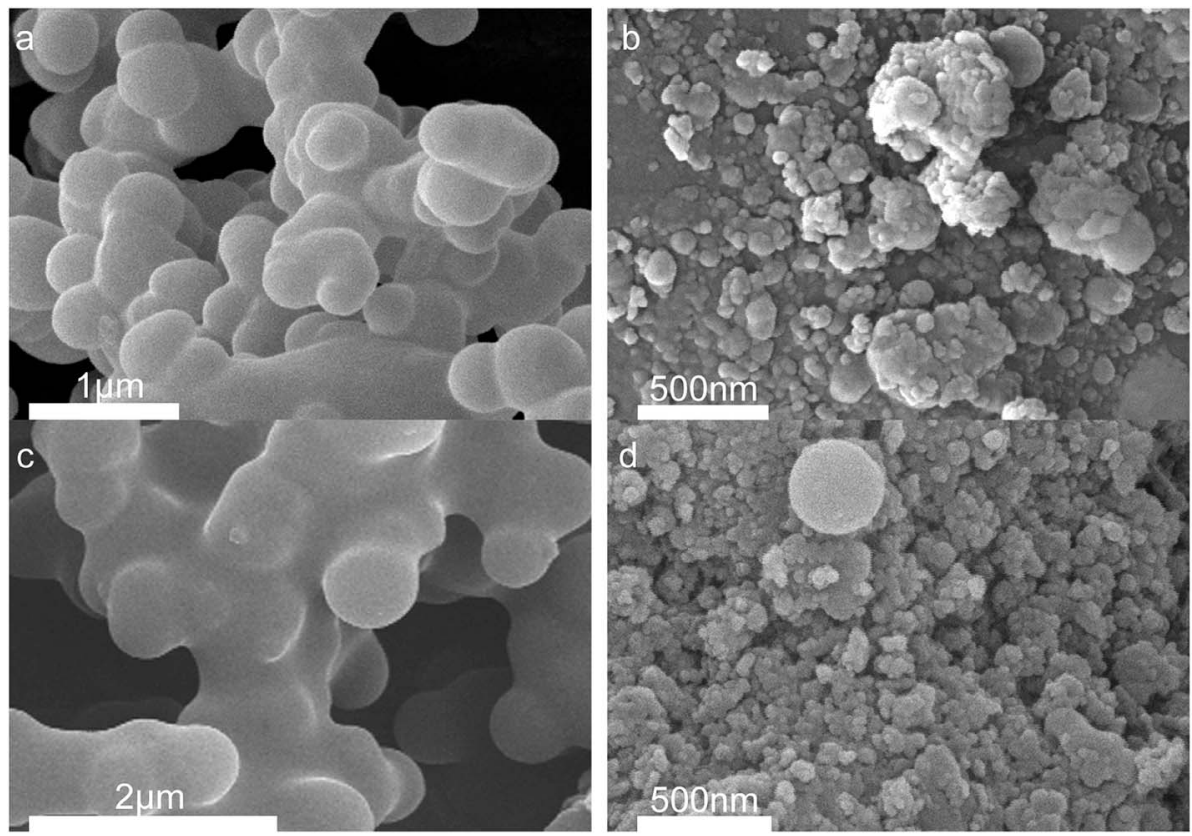

Fig. 5 High magnification SEM images (a) H-150; (b) HMC-150; (c) H-240 and (d) HMC-240.

hydrolysis products or hydrochar would restrict the sizes of hydrochar and facilitate the binding between hydrochar and opal. $^{31-33}$

In order to analyze the impact of the demineralization treatment on the morphology of hydrochar, the SEM analysis of A-H was tested. Fig. 6 demonstrates the morphology of A-H at different time points. The morphology of A-105 retained fiberlike state (Fig. 2(a)). Fig. 2(b) shows the diameter of the spheres is in the range of $5-10 \mu \mathrm{m}$ and the surface of the spheres is quite smooth. The A-240 sample has the same morphology as A-150, and the diameter of spheres is in the range of 5-8 $\mu \mathrm{m}$. These results suggest that demineralization treatment of $\mathrm{H}-X$ has a certain effect on the morphology of A105 , resulting in the appearance of fiber-like morphology due to no hydrochar formed by HTC of HPMC at $105 \mathrm{~min}$. However, demineralization treatment has delicate influence on the morphology of $\mathrm{H}-150$ and $\mathrm{H}-240$ when the hydrochar has formed.

To further confirm the combination between hydrochar and opal, the EDS analysis of HMC-240 was tested. The SEM and relevant EDS pattern of HMC-240 are shown in Fig. 7. Color mapping was performed to visualize the spatial distribution of silicon (Si), carbon (C) and oxygen (O) of HMC-240 (Fig. 7b). Silicon, carbon and oxygen are colored respectively as violet, red and green. The EDS image, and mass ratio and atomic ratio of each element are shown in Fig. 7c. The carbon content (53.33\%) is much higher than silicon content (10.79\%). The high-carbon content property of sample indicates the hydrochar has been formed. From Fig. 7b, the silicon (Si), carbon (C) and oxygen (O) are interlaced with each other. This phenomenon suggests the hydrochar has successfully adsorbed onto the surface of opal. Meanwhile, the appearance of red accumulation area shows the enrichment of hydrochar in opal surface. In addition, Fig. 8b shows the EDS analysis results of some spheroidal particles in white box in Fig. 8a. The carbon content (66.07\%) is higher than other regions; that indicates the some spheroidal particles are just the hydrochar in opal surface. This EDS result is consistent with SEM analysis in Fig. 4 and 5.

\section{$\mathbf{N}_{2}$ adsorption-desorption analysis of solid products}

Table 2 shows the specific surface area, average pore sizes, and average pore volumes of both raw materials and residual solid products. Clearly, the average pore volume and average pore size of HPMC is $0.003 \mathrm{~cm}^{3} \mathrm{~g}^{-1}$, and $11.824 \mathrm{~nm}$ respectively. The three parameters of $\mathrm{H}-120$ slightly increase to $0.022 \mathrm{~cm}^{3} \mathrm{~g}^{-1}$ and $19.372 \mathrm{~nm}$, respectively, but all start to decrease with further prolonging of reaction. The specific surface area values of $\mathrm{H}-X$ series are very low in all cases $\left(<5 \mathrm{~m}^{2} \mathrm{~g}^{-1}\right)$. The three parameters of opal are $80 \mathrm{~m}^{2} \mathrm{~g}^{-1}, 0.223 \mathrm{~cm}^{3} \mathrm{~g}^{-1}$ and $11.227 \mathrm{~nm}$, respectively; after physical mixing with HPMC, the specific surface area and average pore volume significantly decrease to $15 \mathrm{~m}^{2}$ $\mathrm{g}^{-1}$ and $0.052 \mathrm{~cm}^{3} \mathrm{~g}^{-1}$, respectively, indicating HPMC has been already partially adsorbed onto opal surfaces to block the pores of a part of opal, leading to the decline of specific surface area and pore volume..$^{31,32}$ The effects of reaction time on the specific surface area and average pore volume of products in HPMC/ opal systems are consistent with those of HPMC systems, and tend to "first increase and then decrease". These changes are decided by the characteristics of hydrolysis of HPMC and hydrochar production. At the first procedure of HTC, the molecular chains of HPMC are hydrolyzed and broken into small molecules like oligosaccharide, and the reduction in the concentrations of volatile small molecules and HPMC volatile matter would enlarge specific surface area of solid products. ${ }^{3,8}$ After 120 min of reaction, the decrease in specific surface area of solid products is attributed to the gradual formation of hydrochar and the aggregation-induced intense solid products. 


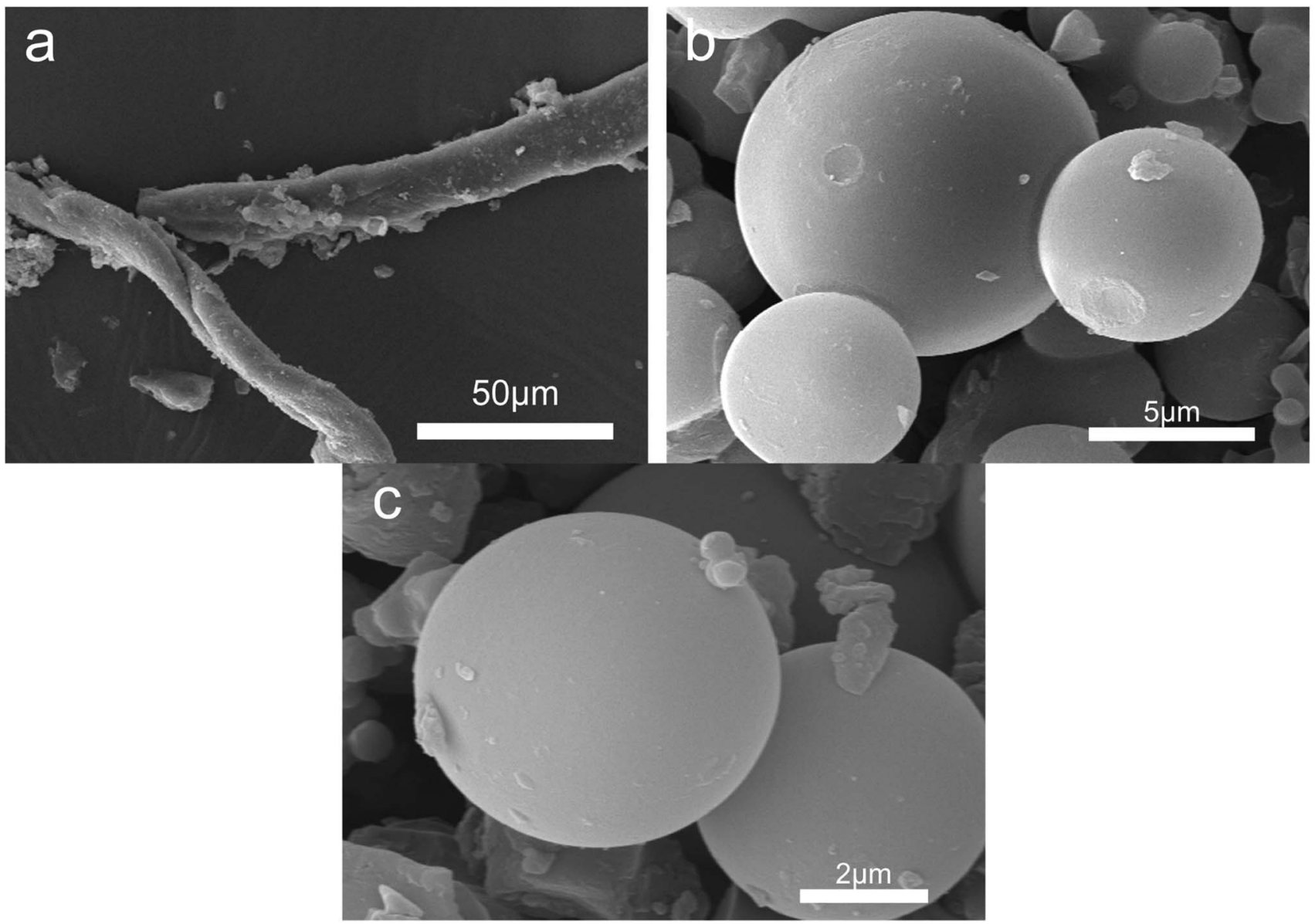

Fig. 6 SEM images (a) A-105; (b) A-150 and (c) A-240.

Fig. 9 shows the $\mathrm{N}_{2}$ adsorption-desorption isotherms and corresponding pore size distributions of $\mathrm{H}-X$ and HMC- $X$. The $\mathrm{N}_{2}$ adsorption-desorption isotherms of HPMC is a typical type II isothermal curve without a hysteresis loop, and with the proceeding of reaction, the isothermal curve of $\mathrm{H}-X$ does not change significantly (Fig. 9a), indicating the reaction time very slightly affects the formation of mesoporous structure of hydrochar. Moreover, the typical IV isothermal curves of opal and HMC- $X$ contain an $\mathrm{H}_{3}$ hysteresis loop (Fig. 9b), indicating the thin-layered wedgy pore channels of HMC- $X$ contain loose particles. The narrower hysteresis loop suggests a part of hydrochar entered the pores of opal and has been adsorbed onto opal. The BJH pore size curves show the pore sizes of HPMC, $\mathrm{H}-105, \mathrm{H}-120, \mathrm{H}-150, \mathrm{H}-180$ and $\mathrm{H}-240$ are 3.9, 3.6, 3.2, 3.2, 3.5 and $3.7 \mathrm{~nm}$, respectively (Fig. 9c). Pore size analysis of HMC- $X$ shows the pore size of opal is about $3.7 \mathrm{~nm}$, but the HMC-105, HMC-120, HMC-150, HMC-180 and HMC-240 all show double peaks, corresponding to pore sizes of $\sim 2.5$ and $9 \mathrm{~nm}$, respectively (Fig. 9d). With the proceeding of reaction, the pore sizes of $\mathrm{H}-X$ first decrease and then increase. With the presence of opal, the appearance of double peaks in HMC- $X$ might be attributed to the binding between opal and hydrochar during reactions.

\section{Composition and $\mathrm{pH}$ of HTC filtrates}

The effects of opal on HPMC hydrolysis were investigated by analyzing the liquid-phase composition after HTC using GC-MS in Fig. 10. After $120 \mathrm{~min}$ of HTC in the HPMC system, the resulting filtrate composed of acidic substances, alcohols and esters (the structure of detected substances shows in Fig. 10a). After 120 min of reaction in the HPMC/opal system, the filtrate is also detected with orcinol and 2-propanol, 1-(2-(2-methoxy-1methylethoxy)-1-methylethoxy), in addition to the components found in the HPMC systems (Fig. 10b). Since orcinol has a phenolic structure, its formation might be due to the opalpromoted cyclic condensation of hydrolysis products. Moreover, due to differences of raw materials and experimental parameters, no formic acid, acetic acid, levulinic acid or glucose are detected in the HPMC system as reported before. ${ }^{\mathbf{4 1 2 , 2 5 , 3 9}}$ After $180 \mathrm{~min}$ of reaction, the components detected in the HPMC system and HPMC/opal system are very similar, including ester, acidic substances, alkanes, alcohols, aromatic substances and other substances (Fig. 10c and d). The presence of aromatic substances indicates the hydrolysis products of HPMC could further dehydrate into aromatically-structured hydrochar. ${ }^{11}$ However, the difference between HPMC system and HPMC/opal system is the presence of furans at the addition with opal (the zoom in box area shows in Fig. 10d). The detected furans in 


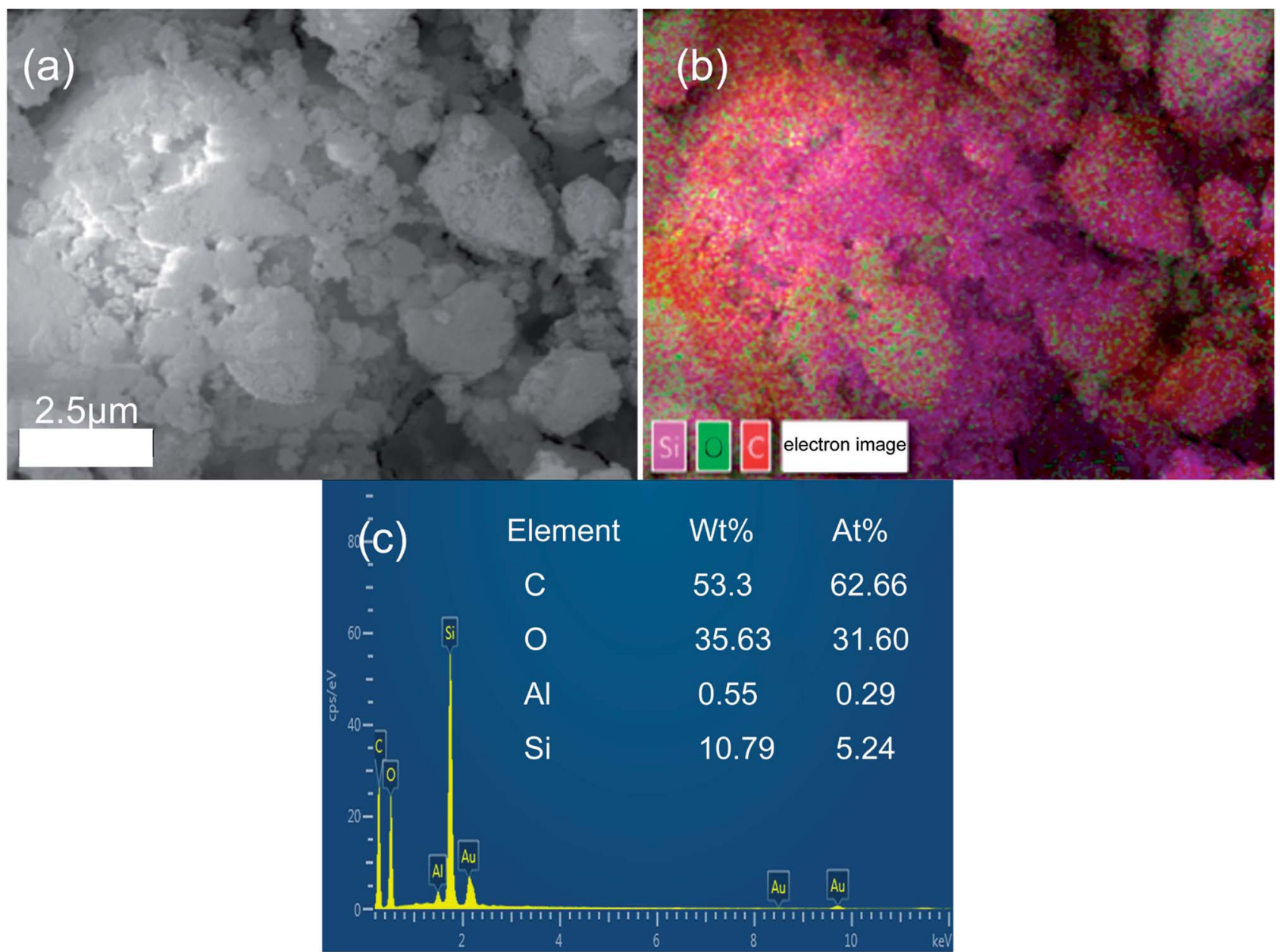

Fig. 7 SEM-EDS analysis of HMC-240 (a) SEM of HMC-240; (b) overall scanning and elements mapping of HMC-240; (c) EDS spectra of HMC240.

HPMC/opal system suggests that opal may promote the formation of furan substances.

With the prolonging of time, the ingredient of acid substance (2-(methoxymethyl)-4-oxopentanoic acid) and esters (hepta-2,4-dienal, methyl acetate) do not change. However the alcohols with ring structure disappear. Above alcohols maybe transform into phenol derivatives (aromatic substance) through dehydration and condensation with the proceeding of reaction. ${ }^{40}$ The formation of esters with ring structure and 1-(2methyl-1-cyclopentenyl)ethanone is done by the cyclization and

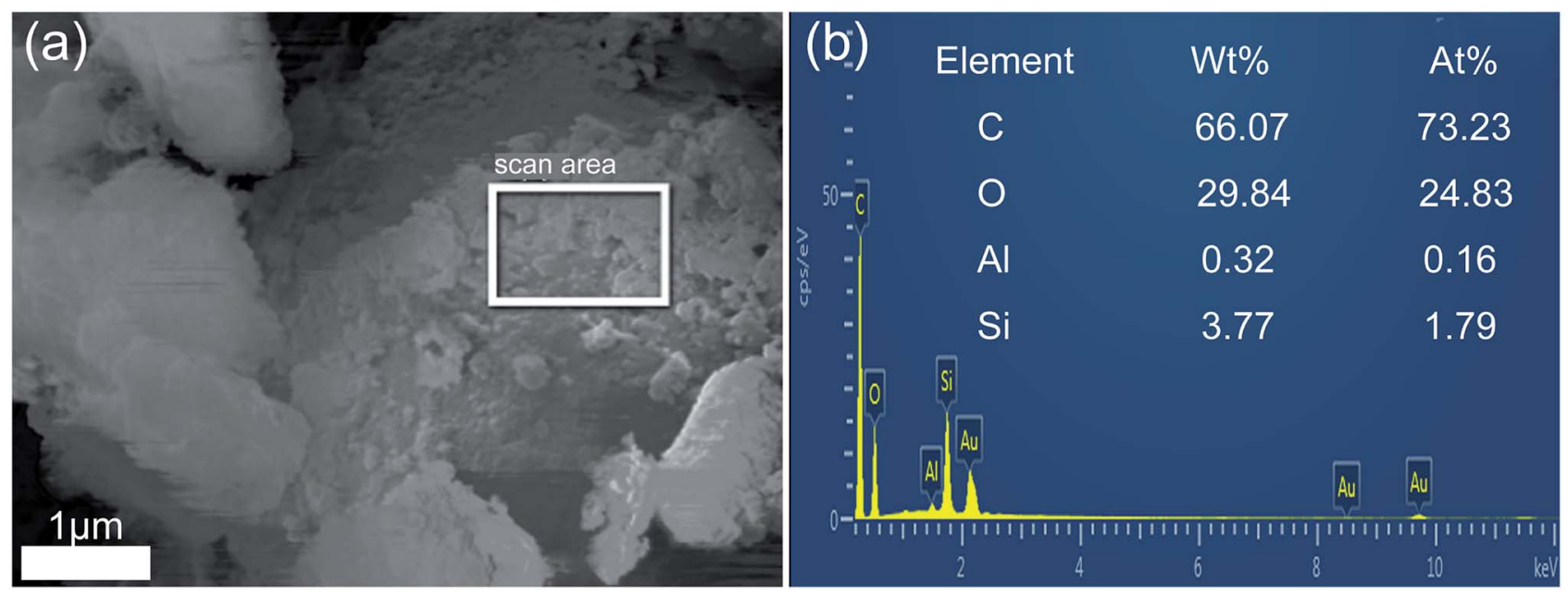

Fig. 8 (a) SEM of HMC-240 and (b) EDS spectra of HMC-240 of scan area in white box. 
Table 2 The specific surface area, pore volume, pore size analysis of raw materials, $\mathrm{H}-X$ and HMC- $X^{a}$

\begin{tabular}{lllllll}
\hline Characterization & & $0 \mathrm{~min}$ & $105 \mathrm{~min}$ & $120 \mathrm{~min}$ & $150 \mathrm{~min}$ & $180 \mathrm{~min}$ \\
\hline Specific surface area $\left(\mathrm{m}^{2} \mathrm{~g}^{-1}\right)$ & HMC- $X$ & 15 & 27 & 32 & 30 & $270 \mathrm{~min}$ \\
Pore volume $\left(\mathrm{cm}^{3} \mathrm{~g}^{-1}\right)$ & H- $X$ & 0.003 & 0.008 & 0.022 & 0.013 & 0.013 \\
& HMC- $X$ & 0.052 & 0.111 & 0.126 & 0.108 & 0.098 \\
Pore size (nm) & H- $X$ & 11.824 & 17.117 & 19.372 & 13.535 & 16.057 \\
& HMC- $X$ & 13.487 & 15.551 & 14.613 & 14.439 & 14.595
\end{tabular}

${ }^{a}$ Opal: specific surface area $80 \mathrm{~m}^{2} \mathrm{~g}^{-1}$, pore volume $0.223 \mathrm{~cm}^{3} \mathrm{~g}^{-1}$, pore size $11.227 \mathrm{~nm}$; specific surface areas of $\mathrm{H}-X<5 \mathrm{~m}^{2} \mathrm{~g}^{-1}$.

dehydration of hydrolysis products with the prolonging of time. ${ }^{41,42}$ Moreover, $\mathrm{pH}$ of filtrate in HPMC/opal systems is always higher than that of the HPMC systems (Fig. 11). GC-MS confirms the filtrates of the HPMC system and HPMC/opal system during carbonization both contained acidic substances. Thus, the higher $\mathrm{pH}$ in the filtrate of the HPMC/ opal systems can be attributed to the fact that the presence of opal restrains the formation of acidic substances during HTC. It is worthy of noting that the production of some toxic compounds is unavoidable during HTC process. The various toxic compounds can be formed such as phenol, furfural, phenol and furan derivatives and polycyclic aromatic hydrocarbon (PAHs) during hydrothermal carbonization biomass. ${ }^{43,44}$ It is important to develop the separation process technology to make best use of above substance. ${ }^{45}$ Moreover, the toxic gas like $\mathrm{CO}, \mathrm{N}_{2} \mathrm{O}, \mathrm{CH}_{2} \mathrm{O}$ can also be produced during HTC process. ${ }^{46}$ Because the HPMC does not contain phosphorus, chlorine or sulfur, the mineral acid could not form during this process. The polycyclic aromatic hydrocarbon (PAHs), furfural and furan derivatives are potential toxicity of the compounds, so the hydrochar included these compounds will be harmful in application of environmental fields. ${ }^{47}$

\section{Mechanism of hydrochar formation}

Cellulose hydrolysis occurs because the increased ion product of $\mathrm{OH}^{-}$and $\mathrm{H}^{+}$under hydrothermal conditions endowed water with both weak acidity and weak basicity and thereby higher reactivity, which promotes the hydrolysis of biomass. ${ }^{24,25}$ As reported, at the hydrothermal condition of $230{ }^{\circ} \mathrm{C}$, first the reactive cellulose is only partially dissolved or converted to colloidal substance, and the subsequent dissolved cellulose hydrolyzes into water-soluble or hydrophobic low polymers (oligosaccharide) and glucose. ${ }^{3-5}$ As hydrothermal reaction proceeded, the low polymers are further decomposed into organic acids (formic acid, acetic acid, levulinic acid), which generate the hydronium ions leading to a rapid decline of $\mathrm{pH}$ to
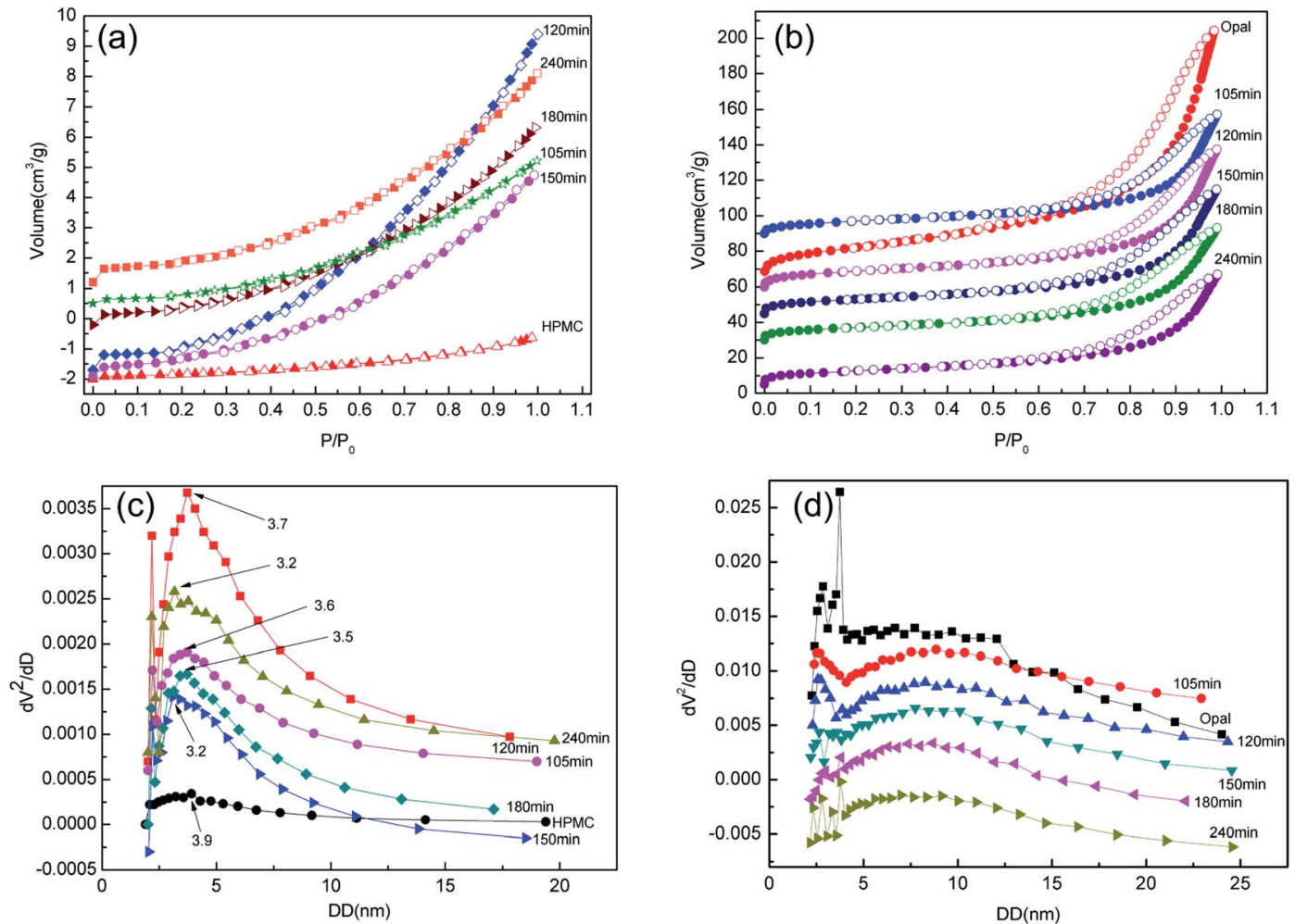

Fig. 9 (a) $\mathrm{N}_{2}$ adsorption-desorption isotherms of $\mathrm{H}-X$; (b) $\mathrm{N}_{2}$ adsorption-desorption isotherms of HMC- $X$; (c) pore size distrubution of $\mathrm{H}-\mathrm{X}$ and (d) pore size distrubution of HMC-X. 

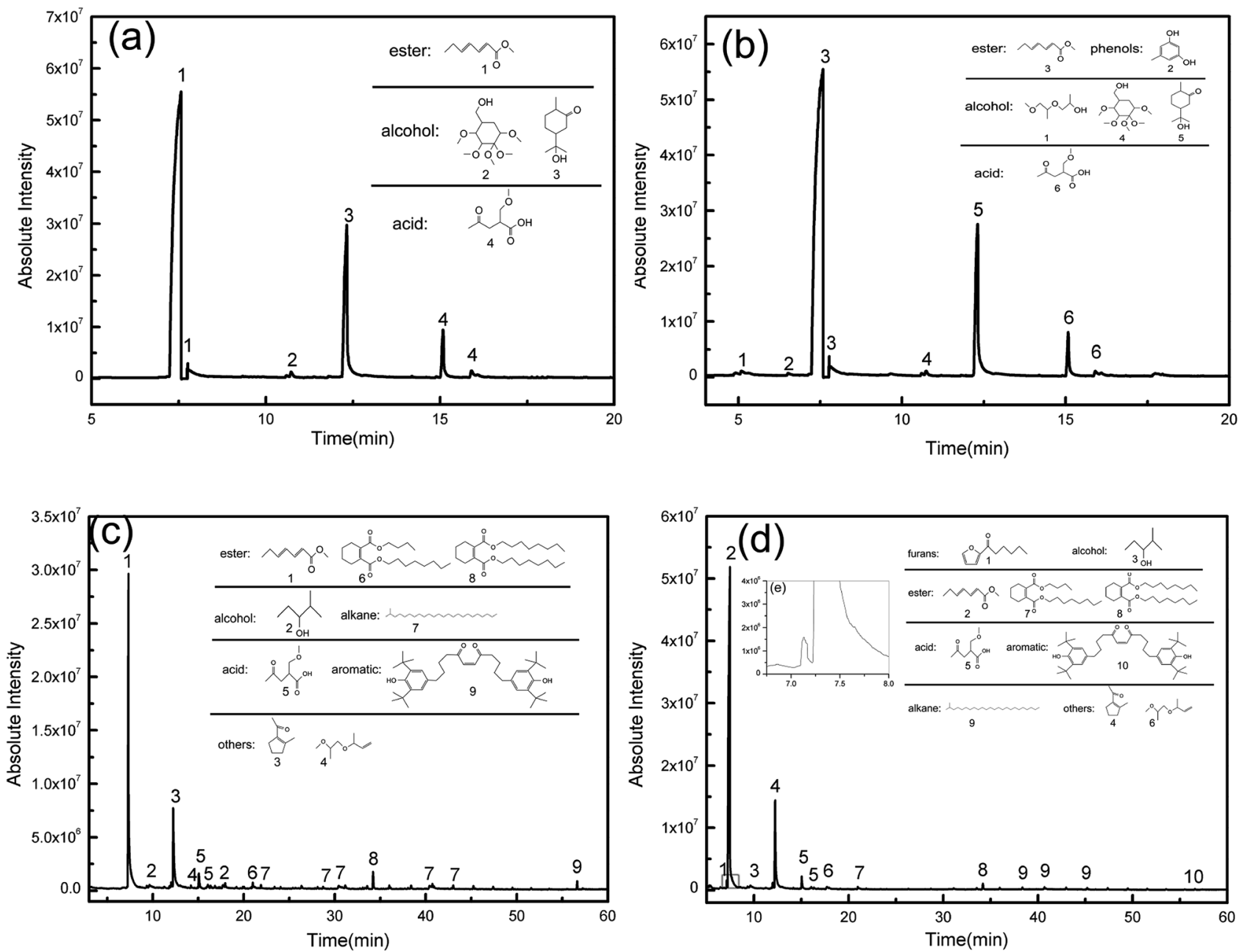

Fig. 10 The GC-MS analysis of liquid of (a) 120 min in HPMC system, (b) 120 min in HPMC/opal system, (c) 180 min in HPMC system, (d) 180 min in HPMC/opal system and (e) the magnified image of the grey box area.

3 in the water solution. ${ }^{28}$ The presence of acidic substances promotes the fracture of hydrogen bonds inside HPMC molecules and accelerates the further hydrolysis of cellulose hydrolysis products. In this period, the water-soluble hydrolysis products further dehydrates and polycondenses into hydrophobic organic matters, which then aggregates into hydrochar. ${ }^{18,25,37}$

GC-MS shows without catalyst or harsh hydrothermal conditions, HPMC would not largely hydrolyze into glucose, fructose or other low polymers (oligosaccharide). ${ }^{5}$ Fig. 12 shows the conversion pathways of substances during the HTC of HPMC. At early procedure of HTC, the large molecular chains of HPMC first hydrolyze into small-molecular cellulose-like intermediates. As time proceeded, the intermediates are structurally broken into nano- or micron-scale cellulose fragments (carbon frame pyrolysis). ${ }^{4}$ These cellulose fragments are further converted, through intramolecular condensation, dehydration and decarbonization, into hydrochar with aromatic networks structure, which has been confirmed by FT-IR (Fig. 3). In other words, the conversion from major part of HPMC to hydrochar is a direct solid-phase to solid-phase conversion; this process is like the direct pyrolysis of lignocellulose into hydrochar with aromatic structure. ${ }^{3}$ During HTC, only a small part of HPMC directly hydrolyzes into glucose and fructose. ${ }^{11,37}$ Then glucose and fructose hydrolyzes into water-soluble intermediates (furans), which are converted through dehydration,

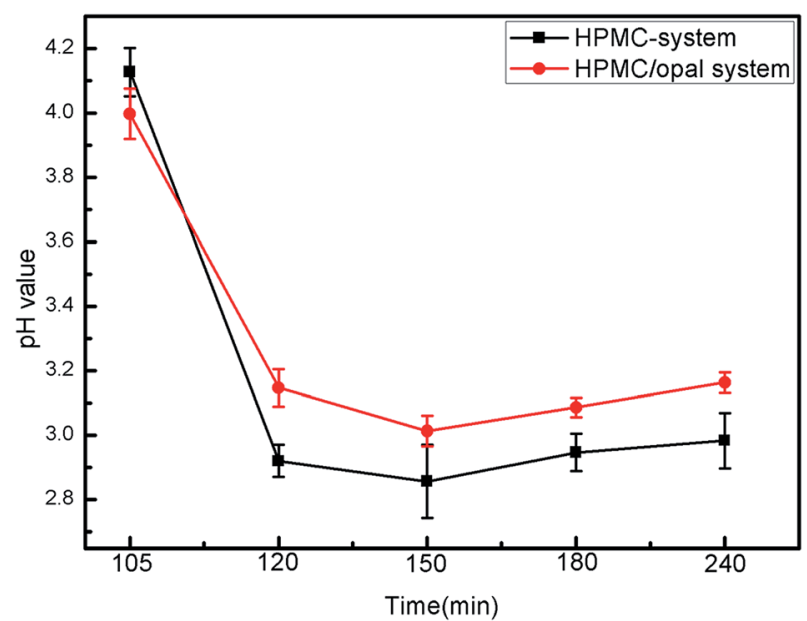

Fig. 11 The $\mathrm{pH}$ value of filtrates in HPMC system and HPMC/opal system. 


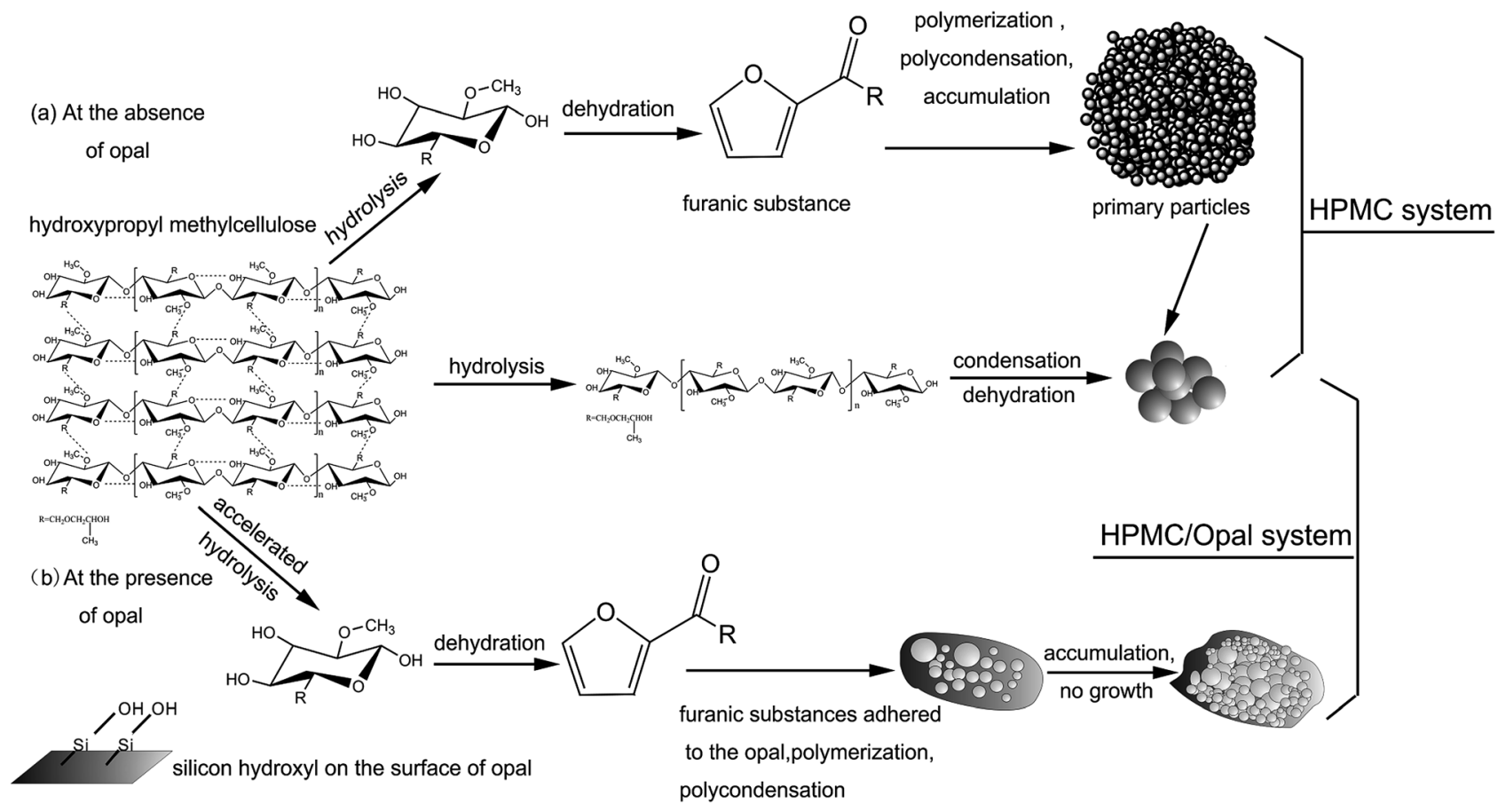

Fig. 12 The mechanism for forming carbonaceous spheres in HPMC system and HPMC/opal system.

polymerization and polycondensation into hydrophobic original particles, which then aggregate and grow up to form spherical hydrochar with hydrophobic aromatic structure. ${ }^{12,25,37}$

Due to the existence of opal, the forming mechanism of large spherical hydrochar is very like that of the HPMC system, but the forming mechanism of nanoscale spherical hydrochar adsorbed onto opal surfaces is different from that of the HPMC system. GC-MS has covered the presence of furans in the filtrates. The above experimental phenomena and other reported experimental results lead to our speculations. Owing to the large specific surface area and better absorption ability, opal superficially adsorbs abundant furans, but its surface silicon hydroxyl group could dehydrate with furans, which tightens the binding between opal and furans. ${ }^{31,32}$ Meanwhile, cross-linking carbon between surface furans can also be formed from the dehydration between active terminal groups (hydroxy terminal, hydrogen terminal), or namely the formation of furan rings. ${ }^{11,12}$ As HTC proceeded, polycondensation between cross-linking carbons gradually occurs, leading to the formation of spherical hydrochar. ${ }^{5,11,38}$ SEM shows the surface hydrochar particles are $20-100 \mathrm{~nm}$ in size, and the nanoscale particles can be formed because opal adsorption reduces the surface energy of hydrochar and inhibits particle aggregation.

The experimental results show that the opal has obvious promoting effect on HPMC hydrothermal carbonization. The study has an exploratory role in selection of natural biomass in follow-up experiments. Also, the study forms scientific understanding of natural mineral associated biomass between inorganic and organic components in the process of carbonization influenced each other. Further, this paper provides a scientific basis for the preparation of new carbon materials for the controlled carbonization of more minerals coexisted in biomass systems.

\section{Conclusions}

By investigating the effects of opal on HTC of HPMC, we found dehydration reaction of HPMC mainly occurred within 105$120 \mathrm{~min}$, afterwards, the hydrochar polycondensation and carbonization were gradually intensified. The $\mathrm{pH}$ of hydrothermal filtrate in HPMC systems was about 3 , and the presence of opal inhibited the formation of acidic substances in the filtrates. The presence of opal significantly accelerated the dehydration, dehydroxylation and small-molecule dissolution during the hydrothermal reactions. The addition of opal made the aromatic hydrochar appear earlier in the solid products, and accelerated the formation of hydrochar. The presence of opal was contributive to the formation of hydrothermal carbon nanospheres $(20-100 \mathrm{~nm})$ in the hydrochar. It is confirmed that minerals could significantly promote HTC of biomass. These findings help to further understand how minerals affect the HTC of biomass, the structures of solid products, and the mechanism of biomass conversion.

\section{Conflicts of interest}

There are no conflicts of interest to declare.

\section{Acknowledgements}

We acknowledged the funding support from the financial support of the National Natural Science Foundation of China (NSFC, grant No. 41472035 and 41702036) and Project of Science and Technology Department (Jilin Province, grant No. 20170201002GX). 


\section{Notes and references}

1 C. He, A. Giannis and J. Wang, Conversion of sewage sludge to clean solid fuel using hydrothermal carbonization: Hydrochar fuel characteristics and combustion behavior, Appl. Energy, 2013, 111, 257-266.

2 X. Lu, B. Jordan and N. D. Berge, Thermal conversion of municipal solid waste via hydrothermal carbonization: Comparison of carbonization products to products from current waste management techniques, Waste Management, 2012, 32, 1353-1365.

3 S. Kang, X. Li, J. Fan and J. Chang, Characterization of hydrochars produced by hydrothermal carbonization of lignin, cellulose, d-xylose, and wood meal, Ind. Eng. Chem. Res., 2012, 51, 9023-9031.

4 C. Falco, F. Perez Caballero, F. Babonneau, C. Gervais, G. Laurent, M. M. Titirici and N. Baccile, Hydrothermal carbon from biomass: structural differences between hydrothermal and pyrolyzed carbons via ${ }^{13} \mathrm{C}$ solid state NMR, Langmuir, 2011, 27, 14460-14471.

5 C. Falco, N. Baccile and M. M. Titirici, Morphological and structural differences between glucose, cellulose and lignocellulosic biomass derived hydrothermal carbons, Green Chem., 2011, 13, 3273-3281.

6 M. M. Titirici and M. Antonietti, Chemistry and materials options of sustainable carbon materials made by hydrothermal carbonization, Chem. Soc. Rev., 2010, 39, 103-116.

7 Q. Wu, W. Li, J. Tan, Y. Wu and S. Liu, Hydrothermal carbonization of carboxymethylcellulose: One-pot preparation of conductive carbon microspheres and watersoluble fluorescent carbon nanodots, Chem. Eng. J., 2015, 266, 112-120.

8 X. Lu, P. J. Pellechia, J. R. V. Flora and N. D. Berge, Influence of reaction time and temperature on product formation and characteristics associated with the hydrothermal carbonization of cellulose, Bioresour. Technol., 2013, 138, 180-190.

$9 \mathrm{Y}$. $\mathrm{Yu}$ and $\mathrm{H}$. Wu, Characteristics and precipitation of glucose oligomers in the fresh liquid products obtained from the hydrolysis of cellulose in hot-compressed water, Ind. Eng. Chem. Res., 2009, 48, 10682-10690.

10 A. Bandura and S. Lvov, The ionization constant of water over wide ranges of temperature and density, J. Phys. Chem. Ref. Data, 2006, 35, 15-30.

11 M. Zhang, H. Yang, Y. Liu, X. Sun, D. Zhang and D. Xue, Hydrophobic precipitation of carbonaceous spheres from fructose by a hydrothermal process, Carbon, 2012, 50, 2155-2161.

12 M. Sevilla and A. Fuertes, The production of carbon materials by hydrothermal carbonization of cellulose, Carbon, 2009, 47, 2281-2289.

13 Y. Xue, B. Gao, Y. Yao, M. Inyang, M. Zhang, A. R. Zimmerman and K. S. Ro, Hydrogen peroxide modification enhances the ability of biochar (hydrochar) produced from hydrothermal carbonization of peanut hull to remove aqueous heavy metals: Batch and column tests, Chem. Eng. J., 2012, 200-202, 673-680.

14 C. Kammann, S. Ratering, C. Eckhard and C. Müller, Biochar and hydrochar effects on greenhouse gas (carbon dioxide, nitrous oxide, and methane) fluxes from soils, J. Environ. Qual., 2012, 41, 1052-1066.

15 I. H. Hwang, H. Aoyama, T. Matsuto, T. Nakagishi and T. Matsuo, Recovery of solid fuel from municipal solid waste by hydrothermal treatment using subcritical water, Waste Management, 2012, 32, 410-416.

16 R. Sun, L. Sun, Y. Chun and Q. Xu, Catalytic performance of porous carbons obtained by chemical activation, Carbon, 2008, 46, 1757-1764.

17 Q. Wang, H. Li, L. Chen and X. Huang, Monodispersed hard carbon spherules with uniform nanopores, Carbon, 2001, 39, 2011-2214.

18 J. G. Lynam, C. J. Coronella, W. Yan, M. T. Reza and V. R. Vasquez, Acetic acid and lithium chloride effects on hydrothermal carbonization of lignocellulosic biomass, Bioresour. Technol., 2011, 102, 6192-6199.

19 R. Rinaldi and F. Schuth, Acid hydrolysis of cellulose as the entry point into biorefinery schemes, ChemSusChem, 2009, 2, 1096-1107.

20 J. G. Lynam, M. T. Reza, V. R. Vasquez and C. J. Coronella, Effect of salt addition on hydrothermal carbonization of lignocellulosic biomass, Fuel, 2012, 99, 271-273.

21 P. R. Patwardhan, J. A. Satrio, R. C. Brown and B. H. Shanks, Influence of inorganic salts on the primary pyrolysis products of cellulose, Bioresour. Technol., 2010, 101, 46464655.

22 K. Raveendran, G. Anuradda and K. C. Khilar, Influence of mineral matter on biomass pyrolysis characteristics, Fuel, 1995, 74, 1812-1822.

23 L. M. Wu, C. H. Zhou, D. S. Tong, W. H. Yu and H. Wang, Novel hydrothermal carbonization of cellulose catalyzed by montmorillonite to produce kerogen-like hydrochar, Cellulose, 2014, 21, 2845-2857.

24 M. Möller, F. Harnisch and U. Schröder, Hydrothermal liquefaction of cellulose in subcritical water-the role of crystallinity on the cellulose reactivity, RSC Adv., 2013, 3, 11035-11044.

25 M. Sevilla and A. B. Fuertes, Chemical and structural properties of carbonaceous products obtained by hydrothermal carbonization of saccharides, Chem.-Eur. J., 2009, 15, 4195-4203.

26 M. Moreno-Recio, J. Santamaría-González and P. MairelesTorres, Brönsted and Lewis acid ZSM-5 zeolites for the catalytic dehydration of glucose into 5hydroxymethylfurfural, Chem. Eng. J., 2016, 303, 22-30.

27 Y. Deng, J. Li, T. Qian, W. Guan, Y. Li and X. Yin, Thermal conductivity enhancement of polyethylene glycol/expanded vermiculite shape-stabilized composite phase change materials with silver nanowire for thermal energy storage, Chem. Eng. J., 2016, 295, 427-435.

28 M. T. Reza, E. Rottler, L. Herklotz and B. Wirth, Hydrothermal carbonization (HTC) of wheat straw: Influence of feedwater $\mathrm{pH}$ prepared by acetic acid and 
potassium hydroxide, Bioresour. Technol., 2015, 182, 336344.

29 Y. Jia and B. Wang, Mineralogy and thermal analysis of natural pozzolana opal shale with nano-pores, J. Wuhan Univ. Sci. Technol., 2017, 32, 532-537.

30 Y. Li, H. Xiao, M. Chen, Z. Song and Y. Zhao, Absorbents based on maleic anhydride-modified cellulose fibers/ diatomite for dye removal, J. Mater. Sci., 2014, 49, 6696-6704.

$31 \mathrm{M}$. Li, Z. Wu and H. Kao, Study on preparation and thermal properties of binary fatty acid/diatomite shape-stabilized phase change materials, Sol. Energy Mater. Sol. Cells, 2011, 95, 2412-2416.

32 S. Karaman, A. Karaipekli, A. Sarı and A. Biçer, Polyethylene glycol (PEG)/diatomite composite as a novel form-stable phase change material for thermal energy storage, Sol. Energy Mater. Sol. Cells, 2011, 95, 1647-1653.

33 J. Dobor, K. Perényi, I. Varga and M. Varga, A new carbondiatomite earth composite adsorbent for removal of heavy metals from aqueous solutions and a novel application idea, Microporous Mesoporous Mater., 2015, 217, 63-70.

34 G. Sheng, S. Yang, J. Sheng, J. Hu, X. Tan and X. Wang, Macroscopic and microscopic investigation of $\mathrm{Ni}(\mathrm{II})$ sequestration on diatomite by Batch, XPS, and EXAFS techniques, Environ. Sci. Technol., 2011, 45, 7718-7726.

35 A. J. R. Anaya, M. Ouzzine, M. A. Lillo-Ródenas and A. L. Solano, Spherical carbons: Synthesis, characterization and activation processes, Carbon, 2014, 68, 296-307.

$36 \mathrm{~S}$. Saka and T. Ueno, Chemical conversion of various celluloses to glucose, Cellulose, 1999, 6, 177-191.

37 Y. Qi, M. Zhang, L. Qi and Y. Qi, Mechanism for the formation and growth of carbonaceous spheres from sucrose by hydrothermal carbonization, RSC Adv., 2016, 6, 20814-20823.

38 M. M. Titirici, M. Antonietti and N. Baccile, Hydrothermal carbon from biomass: a comparison of the local structure from poly- to monosaccharides and pentoses/hexoses, Green Chem., 2008, 10, 1204-1212.
39 X. Lu, J. R. V. Flora and N. D. Berge, Influence of process water quality on hydrothermal carbonization of cellulose, Bioresour. Technol., 2014, 154, 229-239.

$40 \mathrm{H}$. Liu, M. Ma and X. Xie, New materials from solid residues for investigation the mechanism of biomass hydrothermal liquefaction, Ind. Crops Prod., 2017, 108, 63-71.

41 W. Yang, X. Li, Z. Li, C. Tong and L. Feng, Understanding low-lipid algae hydrothermal liquefaction characteristics and pathways through hydrothermal liquefaction of algal major components: Crude polysaccharides, crude proteins and their binary mixtures, Bioresour. Technol., 2015, 196, 99-108.

42 L. Arteaga-Pérez, O. Cápiro, A. Delgado, S. Martín and R. Jiménez, Elucidating the role of ammonia-based salts on the preparation of cellulose-derived carbon aerogels, Chem. Eng. Sci., 2017, 161, 80-91.

43 R. Garlapalli, B. Wirth and M. Reza, Pyrolysis of hydrochar from digestate: Effect of hydrothermal carbonization and pyrolysis temperatures on pyrochar formation, Bioresour. Technol., 2016, 220, 168-174.

44 M. Mihajlović, J. Petrović, S. Maletić, M. Isakovski, M. Stojanović, Z. Lopičić and S. Trifunović, Hydrothermal carbonization of Miscanthus $\times$ giganteus: Structural and fuel properties of hydrochars and organic profile with the ecotoxicological assessment of the liquid phase, Energy Convers. Manage., 2018, 159, 254-263.

45 S. Nizamuddin, H. Baloch, G. Griffin, N. Mubarak, A. Bhutto, R. Abro, S. Mazari and B. Ali, An overview of effect of process parameters on hydrothermal carbonization of biomass, Renewable Sustainable Energy Rev., 2017, 73, 1289-1299.

46 B. Erlach, B. Harder and G. Tsatsaronis, Combined hydrothermal carbonization and gasification of biomass with carbon capture, Energy, 2012, 45, 329-338.

47 H. Lyu, Y. He, J. Tang, M. Hecker, Q. Liu, P. D. Jones, G. Codling and J. P. Giesy, Effect of pyrolysis temperature on potential toxicity of biochar if applied to the environment, Environ. Pollut., 2016, 218, 1-7. 